\title{
Sala de Espera para Gestantes: uma Estratégia de Educação em Saúde
}

\author{
The Prenatal Care Waiting Room as a Setting \\ for Health Education
}

\author{
Débora Souza Santos \\ Adriana Lyzian Alves de Andradel \\ Beatriz Santana de Souza Lima \\ Yasmyny Natash da Silval
}

\section{PALAVRAS-CHAVE: \\ - Educação em Saúde; \\ - Promoção da Saúde; \\ - Enfermagem.}

Recebido em: 26/09/2010

Aprovado em: 19/11/2010

\section{RESUMO}

O objetivo do presente estudo foi descrever as experiências das acadêmicas de enfermagem monitoras do PET-Saúde Enfermagem da Ufal, em 2009/2010, na realização de ações de educação em saúde para gestantes em sala de espera. As ações foram realizadas regularmente na Unidade de Saúde, enquanto as gestantes aguardavam atendimento médico e de enfermagem do pré-natal. Vários temas de interesse para a gestante foram abordados, sempre utilizando métodos criativos e participativos de educação em saúde. Com essas ações, as estudantes aprenderam sobre a dura realidade dessas mulheres e sobre o papel da enfermagem na saúde coletiva, efetivando o cuidar através da educação participativa, em que usuários, familiares e profissionais trabalham juntos para proteger, promover e recuperar a saúde.

\section{ABSTRACT}

The aim of the current study was to describe the experiences of nursing students working as monitors in the Educational Program for Health Work at the UFAL School of Nursing in 2009-2010, conducting health education activities with pregnant women in the prenatal care waiting room. The activities were held regularly at the Health Unit while the women were waiting for medical and nursing prenatal care. Various relevant themes were addressed with creative and participatory health education methods. Through these activities, the students learned about the harsh reality of these women and the role of nursing in public health, implementing more effective care through participatory education, in which users, families, and health professionals work together to protect and promote health. 


\section{INTRODUÇÃO}

O Ministério da Saúde (MS), buscando reformular a orientação profissional dos cursos de saúde das universidades brasileiras, cria desde 2007 programas que estimulam essa modificação, tais como o Pró-Saúde e o PET-Saúde. Com esse intuito, o Programa de Educação pelo Trabalho para Saúde (PET-Saúde) foi instituído por meio da Portaria Interministerial $\mathrm{n}^{\underline{0}}$ 1.802 , de 26 de agosto de 2008, com o objetivo de reformular a orientação profissional dos cursos de saúde das universidades brasileiras. Desse modo, o PET-Saúde da Universidade Federal de Alagoas (Ufal) teve início em 2009 nos cursos de Enfermagem, Medicina, Farmácia, Odontologia e Psicologia, tendo sido expandido, no ano de 2010, para os cursos Nutrição e Serviço Social.

O PET-Saúde no curso de Enfermagem, inserido nesse contexto, buscou também efetivar mudanças na formação profissional, já pactuadas na reforma curricular do curso e que estão em processo de implantação. Almejando contribuir com o fortalecimento da Estratégia Saúde da Família (ESF), focalizou-se no estudo e experimentação de tecnologias leves que favoreçam a promoção da saúde, através da educação, do trabalho em saúde e do controle social ${ }^{1}$.

A proposta do PET-Saúde 2009/2010 foi viabilizar programas de aperfeiçoamento e especialização em serviço dos profissionais da saúde, bem como a inserção dos estudantes da área no cenário da prática, aprimorando a relação ensino-serviço e a integração teórico-prática, tendo como referências principais a política e a realidade de saúde brasileiras. Assim sendo, o programa teve como objetivo a educação em saúde para promoção da qualidade de vida e estímulo ao controle social $^{1}$.

Com a criação do Sistema Único de Saúde (SUS), novas estratégias foram criadas e implementadas visando a criar políticas que atendam à visão da saúde como uma dimensão de qualidade de vida e não simplesmente de ausência de doença. Uma dessas políticas norteadoras é a ESF, a qual tem como papel principal a reorientação da atenção básica, buscando, assim, a integralidade da assistência².

Segundo a Lei Orgânica da Saúde no 8.080, a atenção à saúde pelo SUS deve abranger tanto as ações assistenciais ou curativas quanto, e prioritariamente, as atividades de promoção da saúde e prevenção de doenças ${ }^{3}$. A atenção primária ou básica caracteriza-se pelo atendimento de forma preventiva e promocional, tendo em vista o indivíduo holisticamente, seu contexto social, psicológico e físico, deixando de lado as percepções restritas à cura individual, assumindo, portanto, $\mathrm{o}$ cuidado integral ao indivíduo ${ }^{4}$.
Uma das formas de se realizar promoção da saúde é por meio da educação. Afinal, a educação em saúde constitui um conjunto de saberes e práticas orientados para a prevenção de doenças e promoção da saúde. De acordo com Alves ${ }^{5}$, a educação em saúde:

Trata-se de um recurso por meio do qual o conhecimento cientificamente produzido no campo da saúde, intermediado pelos profissionais de saúde, atinge a vida cotidiana das pessoas, uma vez que a compreensão dos condicionantes do processo saúde-doença oferece subsídios para a adoção de novos hábitos e condutas de saúde ${ }^{5}$.

A Atenção Básica, dentre todos os cenários em saúde, é um contexto privilegiado para o desenvolvimento de práticas educativas em saúde, pois esses serviços são caracterizados pela maior proximidade com a população, com ênfase nas ações de proteção e promoção da saúde ${ }^{6}$.

Para a ESF:

[...] a educação em saúde figura como uma prática prevista e atribuída a todos os profissionais que compõem a Equipe de Saúde da Família. Espera-se que esta seja capacitada para assistência integral e contínua às famílias da área adstrita, identificando situações de risco à saúde na comunidade assistida, enfrentando em parceria com a comunidade os determinantes do processo saúde-doença, desenvolvendo processos educativos para a saúde, voltados à melhoria do autocuidado dos indivíduos ${ }^{7}$.

Assim, considerando as necessidades dos usuários, a sala de espera tem a finalidade de garantir um cuidado humanizado, promovendo a aproximação cada vez maior entre a população e os serviços de saúde. A sala de espera é o lugar onde os usuários aguardam o atendimento dos profissionais de saúde, é um território dinâmico, onde ocorre mobilização de diferentes pessoas a espera de um atendimento de saúde ${ }^{8}$.

A sala de espera não é um espaço voltado para os profissionais de saúde, como o consultório e a enfermaria, mas um espaço público. Ela é o local em que os profissionais da área da saúde tem a oportunidade de desenvolver atividades que extrapolam o cuidado direto, como a educação em saúde, auxiliando na prevenção de doenças e na promoção da saúde. Lá, é possível proporcionar também uma melhora na qualidade do atendimento, garantindo maior acolhimento aos usuários e aperfeiçoando a inter-relação usuário/siste$\mathrm{ma} /$ trabalhador de saúde, além de constituir-se em uma for- 
ma de humanizar, muitas vezes, os burocratizados serviços prestados $^{2}$.

Todavia, a sala de espera, apesar de ser um lugar da instituição de saúde, é um espaço popular que os profissionais de saúde não utilizam de modo constante. Isso ocorre, muitas vezes, por que nesse espaço há interações, nem sempre harmônicas, entre o saber oficial em saúde e o popular, a partir do qual as pessoas expressam sua subjetividade, formas de ser e maneiras de se cuidarem ${ }^{8}$.

Entretanto, os grupos de sala de espera podem funcionar como "espaço potencial". De acordo com Veríssimo e Valle", o grupo de sala de espera pode ser caracterizado como uma forma produtiva de ocupar um tempo ocioso nas instituições, com a transformação do período de espera em momento de trabalho. Nesse espaço, podem ser desenvolvidos processos educativos e de troca de experiências comuns entre os usuários, possibilitando a interação do conhecimento popular com os saberes dos profissionais de saúde.

Por essa razão, há de se concordar com Rodrigues ${ }^{2}$ quando afirma que o enfermeiro:

[...] é um agente fundamental na construção de um fazer em saúde, e, através da ferramenta assistencial sala de espera, o profissional pode compreender as necessidades dos usuários, convocando-os para a coconstrução de alternativas viáveis para solucionar os possíveis problemas que venham a surgir, assim é construído um processo de trabalho em saúde comum entre usuários e profissionais ${ }^{2}$.

Afinal, a educação é uma atividade inerente à enfermagem, a qual contribui para a promoção da saúde, prevenção de agravos e encaminhamentos para outras atividades nessa área.

\section{OBJETIVOS}

\section{Objetivo Geral}

Promover uma melhoria da assistência, com acolhimento e humanização do atendimento, procurando organizar e abordar os assuntos de forma criativa e dinâmica, com a finalidade de obter a atenção das gestantes que aguardam por atendimento.

\section{Objetivos Específicos}

- Promover um aprendizado mútuo entre acadêmicos, profissionais e comunidade.

- Inserir o acadêmico de enfermagem na realidade sociocultural da comunidade.

- Transpor os conhecimentos adquiridos na graduação do curso para além dos muros da Universidade.
- Propiciar aos alunos do grupo PET-Saúde Enfermagem uma ampla formação acadêmica.

- Estimular a mulher a questionar-se sobre o que vem fazendo em relação a si, seu filho e sua família.

\section{MATERIAL E MÉTODOS}

A partir da inserção do PET-Saúde no curso de Enfermagem, os alunos selecionados para participar do projeto proposto foram divididos e inseridos em Unidades de Saúde da Família (USFs). O grupo em questão foi designado para a Unidade de Saúde

Professor Robson Cavalcante de Melo, equipe de saúde 069, Conjunto Freitas Neto, situado no bairro Benedito Bentes II, na cidade de Maceió, Alagoas.

Este relato surgiu das experiências vivenciadas na realização das ações de saúde na sala de espera para gestantes pelas acadêmicas de Enfermagem da Escola de Enfermagem e Farmácia da Universidade Federal de Alagoas participantes do PET-Saúde 2009/2010, no cotidiano do serviço dessa USF. O objetivo do trabalho foi verificar a educação em saúde como forma de promover qualidade de vida e controle social.

A primeira ação realizada foi o reconhecimento da área e da unidade com posterior descrição das observações. Logo após isso, foi elaborado um instrumento para coletar os dados das Fichas A, que posteriormente foram consolidados para uma melhor visualização das necessidades e problemas da comunidade em questão. Foram coletados dados de 50\% de toda a população assistida pela equipe de saúde. A amostra foi escolhida juntamente com a equipe de saúde, em especial com o agente comunitário de saúde (ACS), pois este está em constante contato com a população e a conhece em suas particularidades. Afinal, como afirma Nunes ${ }^{10}$ :

[...] o agente comunitário de saúde (ACS) tem-se revelado o ator mais intrigante no que se refere à relação de trocas estabelecidas entre saberes populares de saúde e saberes médico-científicos. Pode-se dizer que o fato de ser o ACS uma pessoa que convive com a realidade e as práticas de saúde do bairro onde mora e trabalha, e ser formado a partir de referenciais biomédicos, faz deste um ator que veicula as contradições e, ao mesmo tempo, a possibilidade de um diálogo profundo entre esses dois saberes e práticas ${ }^{10}$.

Assim, essa opção facilitou na escolha de uma amostra da população que apresentasse maior diversidade, salientando as condições de saúde, violência, condições socioeconômicas e aspectos específicos da comunidade. A partir da análise situacional, foi possível descrever o perfil epidemiológico da co- 
munidade, incluindo os fatores condicionantes e determinantes do processo saúde/doença e o uso dos indicadores sociais para subsidiar nossas ações de saúde.

O tratamento dos dados coletados foi sistematizado por meio da apuração mecânica manual utilizando-se a técnica dos quadros para a apuração dos dados. Após essa primeira apuração, a partir de planilha construída no Microsoft Office Excel 2007, foi possível transformar os dados e as frequências em tabelas e gráficos. Assim, obteve-se o panorama geral da comunidade adscrita.

Vários foram os problemas de saúde encontrados, todavia, as acadêmicas, juntamente com tutora (professora) e preceptoras (enfermeiras da USF), estudando os dados, resolveram focar o trabalho em um grupo, para que suas ações fos- sem mais bem elaboradas e para que pudessem ser sentidas diferenças substanciais. Em vista dos horários que as acadêmicas frequentavam a unidade, da dinâmica do serviço e da análise situacional, ficou definido que

atuariam com as gestantes que eram atendidas pela enfermeira, médica e dentista nas manhãs de terça-feira. Essa escolha se justificou pelo número aumentado de gestantes adolescentes na área e pela inexistência de grupo de gestantes na unidade.

\section{RESULTADOS E DISCUSSÃO}

As ações foram realizadas todas as terças-feiras das $8 \mathrm{~h}$ às 8h30min, antes do atendimento clínico na sala de reuniões da unidade, promovendo, assim, um ambiente mais tranquilo e

QuAdRO 1

\begin{tabular}{|c|c|}
\hline $\mathrm{AÇ} \tilde{\mathrm{AOO}}$ & OBJETIVOS \\
\hline Quem somos nós? & $\begin{array}{l}\text { Apresentar a proposta do grupo de mulheres em sala de espera. } \\
\text { Possibilitar o diálogo e o surgimento de dúvidas. } \\
\text { Levantar temas/necessidades de interesse das mulheres para planejamento das ações futuras. }\end{array}$ \\
\hline $\begin{array}{l}\text { Acolhimento às gestantes com } \\
\text { automassagem }\end{array}$ & $\begin{array}{l}\text { Acolher as gestantes. } \\
\text { Desenvolver junto a gestantes mecanismos de alívio da dor e desconfortos advindos da } \\
\text { gestação. }\end{array}$ \\
\hline Leite materno: o melhor leite que há! & $\begin{array}{l}\text { Sensibilizar as futuras mães sobre a importância do leite humano. } \\
\text { Informar os componentes do leite materno, enfatizando as diferenças entre o leite comum e o } \\
\text { leite humano. }\end{array}$ \\
\hline $\begin{array}{l}\text { Parto natural - deixe essa ideia nascer em } \\
\text { você! }\end{array}$ & $\begin{array}{l}\text { Sensibilizar as gestantes sobre os benefícios do parto natural. } \\
\text { Informar as diferenças fundamentais entres os diferentes tipos de parto. } \\
\text { Desmistificar o parto normal. } \\
\text { Diminuir medos acerca do parto. }\end{array}$ \\
\hline Verdades e mentiras sobre amamentação & $\begin{array}{l}\text { Informar sobre a importância da amamentação para a mãe e para a criança. } \\
\text { Desmistificar superstições sobre amamentação. } \\
\text { Estimular a amamentação exclusiva até os } 6 \text { meses de idade da criança. } \\
\text { Ensinar técnicas para amamentar. }\end{array}$ \\
\hline Cuidando do seu filho! & $\begin{array}{l}\text { Ensinar cuidados básicos com o recém-nascido (higiene corporal e bucal, sono, cuidado com as } \\
\text { roupas, eliminações vesical e intestinal e lazer). } \\
\text { Estimular o elo entre mãe-filho. }\end{array}$ \\
\hline Antes de ser mãe, sou MULHER! & $\begin{array}{l}\text { Estimular o autocuidado. } \\
\text { Criar um espaço de conversa que não seja relacionado ao gerir/parir. } \\
\text { Estimular a autoestima. }\end{array}$ \\
\hline O que está ocorrendo com meu corpo? & $\begin{array}{l}\text { Orientar a mulher sobre as mudanças ocorridas na gestação. } \\
\text { Minimizar medos acerca da gestação e a transformação corporal. }\end{array}$ \\
\hline Cuidando de mim na gestação & $\begin{array}{l}\text { Estimular o autocuidado. } \\
\text { Ensinar como cuidar da pele, das mamas e da barriga durante a gestação. } \\
\text { Estimular a prática de exercícios físicos leves. }\end{array}$ \\
\hline Planejando minha vida! & $\begin{array}{l}\text { Orientar a mulher sobre o planejamento familiar. } \\
\text { Informar sobre os métodos contraceptivos. }\end{array}$ \\
\hline $\begin{array}{l}\text { Dias das Mães! Por que nós mulheres } \\
\text { somos importantes para o mundo? }\end{array}$ & $\begin{array}{l}\text { Criar elos entra a usuária gestante e a Unidade de Saúde. } \\
\text { Estimular a autoestima. } \\
\text { Estimular o autocuidado em qualquer fase da vida. } \\
\text { Criar espaços abertos de fala e escuta. } \\
\text { Estimular a vinda da gestante à Unidade de Saúde. }\end{array}$ \\
\hline
\end{tabular}

$65 \mid$\begin{tabular}{l|l} 
REVISTA BRASILEIRA DE EDUCAÇ̃̃̃O MÉDICA \\
$36(1$ Supl. 2):62 - 67; 2012
\end{tabular}


confortável para solucionar dúvidas, diminuir anseios, medos e trocar conhecimentos. Afinal, concordando com Teixeira e Veloso ${ }^{8}$ :

O lidar com o cotidiano das práticas de saúde favorece contatos com a realidade de nossa clientela, que é diversificada, envolvida por dimensões econômicas, sociais e pluriculturais. Esse convívio com as pessoas atendidas nos serviços de saúde envolve saberes, práticas, mitos, tabus e representações, que fazem parte da subjetividade coletiva e que nem sempre compartilham com os princípios da racionalidade científica moderna. Logo, esses conteúdos precisam ser compreendidos e abordados de modo sensível e instrumental na prática educativa em enfermagem ${ }^{8}$.

Foram abordados assuntos referentes a tipos de parto, em especial o natural; alívio da dor por meio da automassagem; amamentação; cuidados com o corpo e as mamas; cuidado com o recém-nascido; planejamento familiar; e sexualidade na gravidez. Os objetivos gerais desses encontros foram, principalmente, promover espaços onde a gestante se sentisse acolhida e pudesse expor suas dúvidas, anseios e medos, além de tentar desenvolver formas educativas não convencionais para as salas de espera. Para cada ação escolhida foi elaborado um planejamento específico, constando o título, objetivos a serem alcançados e estratégias da ação. Os títulos e objetivos das ações realizadas podem ser visualizados no quadro 1 .

Foram utilizadas metodologias diferentes para as dinâmicas de grupo, como, por exemplo, a montagem com cartolinas e revistas do corpo feminino idealizado pelas mulheres, levando-as a refletir sobre as questões de gênero e os tabus da sociedade. Outras estratégias utilizadas foram vídeos educativos, rodas de conversa, palestra com convidados, entre outros.

A atuação com esse grupo em especial foi um desafio, pois na unidade não existia um grupo de gestantes e as ações em saúde eram realizadas no consultório com o profissional, sem trocas coletivas de conhecimentos e experiências, as quais são muito importantes nos grupos. Além disso, os indicadores de saúde sinalizavam para o elevado número de gestantes adolescentes.

De acordo com Delfino ${ }^{11}$, o que se vê nos serviços de saúde, há anos, é a assistência à gestante oferecida quase que exclusivamente vinculada à consulta individual, seja médica ou de enfermagem. Essas ações de saúde não propiciam um acolhimento adequado às ansiedades, às queixas e temores associados culturalmente à gestação. Logo, o gerar é conduzido pelos profissionais de saúde de modo intervencionista, tornando a assistência e as atividades educativas fragmenta- das, sem que a realidade da mulher gestante seja tratada na sua integralidade ${ }^{11}$.

Durante o planejamento e inicial desenvolvimento das atividades, observou-se uma resistência das mulheres, mostrando dificuldade ao se posicionar, expressar suas dúvidas nas discussões sobre o próprio corpo, planejamento familiar e sexualidade na gravidez. Os tabus sociais e o medo de errar diante dos profissionais de saúde criavam uma barreira entre essas mulheres e sua própria saúde.

Capra $^{12}$ afirma que o conceito de saúde está fortemente ligado ao contexto cultural em que ele ocorre. Nesse aspecto, as participantes estavam acostumadas a falarem apenas dentro do consultório quando lhes era permitido e, nem sempre, tinham suas necessidades atendidas.

O que se sentiu e observou é que, quando se trabalha com educação em saúde, trabalha-se também com as questões expressivas do ser e as representações culturais de uma população. Acredita-se que a sala de espera possa ser cada vez mais aperfeiçoada como um recurso de educação em saúde, no qual o enfermeiro pode se apropriar desse local para acolhimento e promoção de saúde, pois educar, segundo Patrício ${ }^{13}$, representa:

[...] um processo cultural, ou seja, um processo de interações humanas fundamentado em suas crenças, seus valores, seus conhecimentos e suas práticas, incluindo aquelas de participação política, aprendidas/ensinadas de diferentes maneiras através da sua história de vida, e que guiam, de certa forma, suas ações no cotidiano do processo de viver ${ }^{13}$

Foi possível identificar que o desenvolvimento dessa sala de espera fez com que as estudantes de enfermagem participantes do projeto interagissem com a comunidade de forma a entendê-la dentro de seu contexto, respeitando sua cultura e dimensão social, fato que despertou curiosidade e interesse das mulheres pelo conhecimento.

Constatou-se que as realizações das salas de espera estreitaram os laços entre a comunidade e a equipe de saúde, modificando o quadro de uma equipe que deposita saberes em uma comunidade, para o de uma equipe que troca conhecimentos com a comunidade. Dessa forma, foi possível formar um grupo de mulheres dedicadas e disponíveis ao intercâmbio de informações, sendo participativas nas dinâmicas, palestras e oficinas realizadas.

O último encontro foi realizado no dia 8 de maio de 2010, Dia Internacional da Mulher. Foi acordado com a equipe que, nesse dia, a manhã seria reservada totalmente para a realiza- 
ção de um grande encontro para celebrar a data, o feminino e a maternidade. Toda a equipe da unidade participou do evento, houve distribuição de lanches e presentes, mas o mais importante foi que as mulheres, a partir das dinâmicas realizadas, deram depoimentos emocionados de como as ações foram significativas, pois elas puderam superar o caráter usual, constituindo momentos de escuta aberta, na qual não tinham receio de falar e tirar suas dúvidas.

\section{CONSIDERAÇÕES FINAIS}

A construção da sala de espera revelou-se como um espaço de compartilhamento de experiências, sentimentos, afetos e socialização dos saberes técnico-científico e popular. Ocasionou, ainda, uma maior compreensão sobre as acadêmicas de enfermagem e seu papel de cidadãs e futuras enfermeiras.

Assim, a sala de espera como estratégia de educação em saúde oportunizou, na experiência aqui relatada, a aproximação da mulher gestante com o serviço, tornando-a protagonista de seu processo saúde-doença, ao mesmo tempo em que contribuiu para orientá-la em relação à sua corresponsabilidade. Atividades em sala de espera viabilizam, assim, a atuação do enfermeiro como educador em saúde, efetivando o cuidar da enfermagem na saúde coletiva, por meio da educação participativa, em que usuários, familiares e profissionais trabalham juntos para proteger, promover e recuperar a saúde.

\section{REFERÊNCIAS}

1. Universidade Federal de Alagoas.. Termo de Compromisso. PET-saúde institucional; 2009.

2. Rodrigues AD, Dallanora CR, Rosa J, Germani ARM. Sala de espera: uma ambiente para efetivar a educação em saúde. Vivências. 2009; 5(7): 101-6

3. Carvalho GI, Santos L. Sistema Único de Saúde: comentários à lei orgânica de saúde (Leis no 8.080/90 e no 8.142/90). 3 ed. Campinas: Ed. Unicamp; 2002. p.33-53.

4. Alves VS. Um modelo de educação em saúde para o Programa Saúde da Família: pela integralidade da atenção e reorientação do modelo assistencial. Interface (Botucatu)]. 2005;9(16): 39-52.

5. Costa M, López E. Educación para la salud. Madrid: Pirámide; 1996. p. 25-58.
6. Vasconcelos EM. Educação popular e a atenção à saúde da família. São Paulo: Hucitec; 1999.

7. Brasil. Ministério da Saúde. Saúde da Família: uma estratégia para a reorientação do modelo assistencial. Brasília: MS;1997.

8. Teixeira ER, Veloso RC. O grupo em sala de espera: território de práticas e representações em saúde. Texto contexto - Enferm. 2006; 15(2): 320-5.

9. Veríssimo DS, Valle ERM. A experiência vivida por pessoas com tumor cerebral e por seus familiares. Psicologia Argumenta/Pontifícia Universidade do Paraná. Curitiba: Champagana. 2006; 24(45): p. 4.

10. Nunes MO. O agente comunitário de saúde: construção da identidade desse personagem híbrido e polifônico. Cad Saúde Pública; 2002;18(6): 1639-46.

11. Delfino MRR. O processo de cuidar participante com um grupo de gestantes: repercussões na saúde integral individual coletiva. Tubarão; 2003. Dissertação [Mestrado] - Universidade do Sul de Santa Catarina.

12. Capra F. O ponto de mutação: a ciência, a sociedade e a cultura emergente. 23 ed. Cultrix: São Paulo; 2002.

13. Patrício ZM. "Educação para a saúde": um processo de interações cultural-afetivas transformando a vida. Florianópolis: UFSC. Trabalho apresentado no $47^{\circ}$ Congresso Brasileiro de Enfermagem, Goiás, 1995.

\section{CONTRIBUIÇÃO DOS AUTORES}

Débora de Souza Santos participou da concepção e elaboração do artigo. Adriana Lyzian Alves da Andrade, Beatriz Santana de Souza Lima e Yasmyny Natash da Silva participaram da concepção, desenho e elaboração do artigo.

\section{CONFLITO DE INTERESSES}

Declarou não haver.

\section{ENDEREÇO PARA CORRESPONDÊNCIA}

Débora Souza Santos

Av. Hamilton Falcão, 376, Qd. E - Lt. 1

Santa Amélia - Maceió

CEP. 57063-250 AL

E-mail: ssdebora@yahoo.com.br 